\title{
COPB2 suppresses cell proliferation and induces cell cycle arrest in human colon cancer by regulating cell cycle-related proteins
}

\author{
YAN WANG $^{1-3}$, ZHI CHAI $^{3}$, MIN WANG $^{1,2}$, YANLING JIN $^{1,2}$, AIJUN YANG $^{1,2}$ and MIN LI ${ }^{1,2}$ \\ ${ }^{1}$ Institute of Integrated Traditional Chinese and Western Medicine; ${ }^{2}$ Institute of Pathology, \\ School of Basic Medical Sciences, Lanzhou University; ${ }^{3}$ Department of Telemedicine Consultation Centre, \\ Gansu Provincial Hospital, Lanzhou, Gansu 730000, P.R. China
}

Received June 22, 2017; Accepted October 31, 2017

DOI: $10.3892 /$ etm.2017.5506

\begin{abstract}
Coat proteins (COPs), including the major types clathrin, COPI and COPII, play a considerable role in intracellular transport by initiating the formation of transport vesicles. Coatomer protein complex subunit $\beta 2$ (COPB2) is one of the seven subunits that make up a COPI complex. In the present study, we found that COPB2 was highly expressed in human colon cancer specimens. However, to date, there have been no reports describing the functions of COPB2 in human colon cancer cells. In this study, we analyzed the functions of COPB2 in the proliferation and cell cycle arrest of human RKO and HCT116 colon cancer cells by using lentivirus-mediated RNAi infection. Our results demonstrated that the silencing of COPB2 in vitro could inhibit the proliferation and colony formation abilities of RKO and HCT116 cells. Furthermore, measurement of cell cycle distribution indicated that the downregulation of COPB2 could induce G0/G1 or $\mathrm{S}$ phase cell cycle arrest by regulating cell cycle-related proteins. In conclusion, our results suggest that COPB2 plays a key role in the proliferation and cell cycle progression of human RKO and HCT116 colon cancer cells, thus indicating that COPB2 might be a potential therapeutic target for the treatment of human colon cancer.
\end{abstract}

\section{Introduction}

Colorectal cancer (CRC) is among the most common malignant human tumors, with nearly 1.2 million new cases and more than 600,000 CRC-related mortalities reported each year worldwide $(1,2)$. The treatment of CRC has greatly developed in the past several decades, and surgery and chemotherapy have been widely used to improve the survival rate and prognosis of $\mathrm{CRC}$ patients. The 5-year relative survival rate of CRC patients

Correspondence to: Professor Min Li, Institute of Pathology, School of Basic Medical Sciences, Lanzhou University, 199 West Donggang Road, Lanzhou, Gansu 730000, P.R. China

E-mail: wangyanimmunity@126.com

Key words: coatomer protein complex subunit $\beta 2$, colon cancer, lentivirus, proliferation, cell cycle is $90.1 \%$ for those with early-stage disease; however, this drops to 69.2 and $11.7 \%$ for those presenting with regional spread or distant metastases, respectively (3). With the use of colonoscopy, the survival rate of CRC patients has improved in some developed countries, though there is no obvious improvement in China (4).

To develop effective drugs for the treatment of CRC, it is important to identify therapeutic target genes or molecules. Coat proteins (COPs) include three main types of protein (clathrin, COPI and COPII) and play a key role in intracellular transport by forming transport vesicles. This role is achieved through the coupling of two major functions. Membrane bending to generate transport carriers from organellar membranes; and cargo binding for the packaging of newly formed vesicles (5). The core component of the COPI complex is a protein coatomer, a multimeric complex comprising seven subunits: $\alpha-\mathrm{COP}$ (160 kDa), $\beta$-COP (110 kDa), $\beta$ '-COP (110 kDa), $\gamma$-COP $(98 \mathrm{kDa})$, $\delta$-COP (61 kDa), $\varepsilon$-COP (36 kDa), and $\zeta-C O P(20 \mathrm{kDa})(6,7)$. Coatomer protein complex subunit $\beta 2$ (COPB2) is one of the seven non-clathrin-coated vesicular coat subunits that forms the coatomer, and plays a role in membrane transport between the endoplasmic reticulum and Golgi apparatus (8-11). However, to the best of our knowledge, the relationship between the expression of COPB2 and the development of colon cancer remains unknown. Therefore, the present study examined the expression of COPB2 in human colon cancer tissues, paracancerous tissues and colon cancer cell lines. Furthermore, to investigate the physiological function of COPB2 in colon cancer, we used a lentivirus-mediated RNAi method to suppress the expression of COPB2 in RKO and HCT116 colon cancer cells. In the present study, we found that COPB2 reduced the proliferation and colony-formation abilities of colon cancer cells. Furthermore, COPB2 silencing was associated with $\mathrm{G} 0 / \mathrm{G} 1$ or $\mathrm{S}$ phase cell cycle arrest; and after COPB2 silencing, the expression level of P21 and P16 were significantly increased, while that of cyclin A was reduced. Based on the present findings, we hypothesize that COPB2 is essential for the proliferation of colon cancer cells, and that lentivirus-mediated COPB2 silencing may be a promising therapeutic method for the treatment of colon cancer.

\section{Materials and methods}

Immunohistochemistry (IHC). Tumor specimens and adjacent noncancerous tissues from 35 patients who underwent 
surgery for colon cancer in Gansu Provincial Hospital (Gansu, China) in 2016 were evaluated in this study. Ethics committee approval was obtained from the Ethics Committee of Gansu Provincial Hospital. All tumor specimens were obtained from patients who had been newly diagnosed with colon cancer, and none of the patients had received chemotherapy or radiotherapy prior to sample collection. IHC was performed to detect COPB2 protein expression by tissue microarray as described previously (12). In brief, the sections were deparaffinized in xylene and dehydrated with an ethanol gradient, and then blocked with $0.3 \% \mathrm{H}_{2} \mathrm{O}_{2}$ at room temperature for $10 \mathrm{~min}$ to inhibit endogenous peroxidase activity. Blocking with $10 \%$ normal goat serum was performed prior to the application of primary antibody against COPB2 (HPA036867, 1:10; Sigma-Aldrich, St. Louis, MO, USA). Subsequently, the sections were incubated with the anti-COPB 2 antibody in PBS at $4^{\circ} \mathrm{C}$ overnight. The slides were then probed for $10 \mathrm{~min}$ with an HRP-labeled polymer conjugated to an appropriate secondary antibody. The immunoreactive bands were detected by staining with DAB. The slides were reviewed and scored in a double-blinded manner by two independent pathologists. More than 1,000 cells were counted at $\mathrm{x} 400$ magnification in ten visual fields selected at random. The proportions of positive cells were scored as follows: ' 0 ', no staining; ' 1 ', <1/3 stained; ' 2 ', 1/3-2/3 stained; and ' 3 ', $>2 / 3$ stained. The staining intensity was scored as follows: ' 0 ', none; ' 1 ', weak; ' 2 ', intermediate; and ' 3 ', strong. The two scores were added to obtain the final scores, which ranged from 0 to 6 . A final score of $0-1$ indicated negative staining (-), 2-3 indicated weakly positive staining (+), 4 indicated moderately positive staining (++), and 5-6 indicated strongly positive staining $(+++)(13)$.

Cell culture. Six human CRC cancer cell lines, namely RKO, SW480, HCT116, DLD1, HT-29 and SW620, were obtained from the Cell Bank of Type Culture Collection of Chinese Academy of Sciences (Shanghai, China). All cells were maintained in RPMI 1640 medium (Hyclone; GE Healthcare Life Sciences, Logan, UT, USA) containing 10\% FBS (R\&D Systems, Inc., Minneapolis, MN, USA), L-glutamine, and $100 \mathrm{U} / \mathrm{ml}$ penicillin/streptomycin (Gibco; Thermo Fisher Scientific, Inc., Waltham, MA, USA) at $37^{\circ} \mathrm{C}$ in a $5 \% \mathrm{CO}_{2}$ incubator.

Measurement of COPB2 expression in colon cancer cell lines. The expression of COPB2 in the human cancer cell lines RKO, SW480, HCT116, DLD1, HT-29, and SW620 was detected by reverse transcription-quantitative PCR (RT-qPCR). Total RNA was extracted from the different cell lines using TRIzol reagent (Invitrogen, Carlsbad, CA, USA) according to the manufacturer's instructions. The primers used to measure the expression of COPB2 were 5'-GTG GGGACAAGCCATACCTC-3' (forward) and 5'-GTGCTC TCAAGCCGGTAGG-3' (reverse). The primers for GAPDH, which was used as an internal control, were 5'-TGACTTCAA CAGCGACACCCA-3' (forward) and 5'-CACCCTGTTGCT GTAGCCAAA-3' (reverse). The reaction system was made up as follows: $10 \mu$ l SYBR premix Ex Taq; $2 \mu$ l forward and reverse primers $(2.5 \mu \mathrm{M}) ; 2 \mu \mathrm{l}$ cDNA; and $4 \mu \mathrm{l}$ RNase-Free $\mathrm{H}_{2} \mathrm{O}$. The conditions used for qPCR were as follows: Initial denaturation at $95^{\circ} \mathrm{C}$ for $15 \mathrm{sec}$, denaturation at $95^{\circ} \mathrm{C}$ for $5 \mathrm{sec}$, and annealing/extension at $60^{\circ} \mathrm{C}$ for $30 \mathrm{sec}$ (for a total of 45 cycles). Fold changes in expression were calculated using the $2^{-\Delta \Delta \mathrm{Cq}}$ method. The experiment was repeated 3 times.

Vector construction and lentivirus packaging. An shRNA targeting COPB2 (shCOPB2; AGATTAGAGTGTTCAATTA) and a random negative control shRNA (shCtrl; TTCTCCGAA CGTGTCACGT) were designed. Both shRNAs were inserted into GV248 lentiviral vectors (Shanghai GenePharma Co., Ltd., Shanghai, China). For lentivirus packing, HEK293T cells were transfected with the GV248-sh COPB2 or -shCtrl vectors using Lipofectamine 2000, according to the manufacturer's protocol.

Lentivirus-mediated silencing of COPB2 in colon cells. RKO and HCT116 cells $\left(1 \times 10^{5}\right.$ cells $\left./ \mathrm{ml}\right)$ were cultured in 6-well plates. After 24 h, GV248-COPB2-shRNA or -control shRNA were used to infect RKO and HCT116 cells with multiplicities of infection (MOIs) of 5 and 15, respectively. At $96 \mathrm{~h}$ post-infection, the cells were observed under a fluorescence microscope (x100). The infection efficiency was determined by counting the number of GFP-expressing cells.

RNA extraction and RT-qPCR. At $96 \mathrm{~h}$ post-infection, RKO and HCT116 cells were collected and total RNA was extracted with TRIzol reagent (Invitrogen) according to the manufacturer's instructions. RT-qPCR was performed to determine the knockdown efficiency of the COPB2 gene in the RKO and HCT116 cells infected with shCOPB2. The primers used to measure the expression levels of COPB2 and GAPDH, the reaction system and the qPCR conditions were the same as above. Fold changes in expression were calculated using the $2^{-\Delta \Delta \mathrm{Ct}}$ method, and the experiment was repeated 3 times.

Western blot analysis. Western blot analysis was performed as previously described (14). Briefly, at $96 \mathrm{~h}$ post-infection, the RKO and HCT116 cells were collected and total protein was extracted. Protein samples were then separated on a $10 \%$ SDS-PAGE gel and transferred to polyvinylidene difluoride (PVDF) membranes (EMD Millipore, Bedford, UK). After blocking with 5\% skim milk, the membranes were exposed to primary antibodies against COPB2 (Sigma-Aldrich), P16, P21, cyclin A1-A2 (Abcam, Cambridge, UK) and GAPDH (Abcam) overnight at $4^{\circ} \mathrm{C}$. After washing three times with TBST, the membranes were incubated with fluorescently labeled secondary antibodies at room temperature for $1 \mathrm{~h}$. The bands were visualized with an Odyssey detection system (Licor Biosciences, Nebraska, US). The experiment was repeated 3 times.

MTT cell proliferation assay. An MTT assay was used to assess the proliferation of the RKO and HCT116 cells infected with shCOPB2 or shCtrl, as previously described $(15,16)$. In brief, after being infected $96 \mathrm{~h}$, the two cell lines were seeded in 96-wells plates at a density of $1 \times 10^{4}$ cells/well, and cell density was measured at days 1, 2, 3, 4 and 5 after seeding. At each time point, $20 \mu \mathrm{l}$ of 3-(4,5-dimethylthiazol-2-yl)-2,5-dip henyltetrazolium bromide (MTT) solution was added to each well. After $4 \mathrm{~h}$ of incubation, the MTT was removed, $150 \mu \mathrm{l}$ of DMSO was added, and the plate was shaken constantly for 
Table I. Expression of COPB2 in human colon cancer and paracancerous tissue by IHC staining.

\begin{tabular}{lccc}
\hline Group & Case number & Mean \pm SD & P-value \\
\hline Colon cancer & 35 & $4.60 \pm 1.418$ & $<0.001$ \\
Paracancerous tissue & 35 & $1.17 \pm 1.098$ & \\
\hline
\end{tabular}

COPB2, coatomer protein complex subunit $\beta 2$; SD, standard deviation; IHC, immunohistochemical.

$15 \mathrm{~min}$. The absorbance was read using a microplate reader at a wavelength of $490 \mathrm{~nm}$. The experiment was repeated 3 times.

BrdU incorporation assay. A BrdU Cell Proliferation ELISA kit (11647229001; Roche Diagnostics, Basel, Switzerland) was used to measure the proliferation ability of cells based on DNA synthesis rate, according to the manufacturer's protocol. After being infected $96 \mathrm{~h}$, the RKO and HCT116 cells were incubated with BrdU labeling solution (10 $\mu \mathrm{l} / \mathrm{well})$, and then with fixing solution $(200 \mu \mathrm{l} / \mathrm{well})$ at room temperature in the dark. After $30 \mathrm{~min}$, the cells were incubated with anti-BrdU-POD (100 $\mu \mathrm{l} /$ well) for another $90 \mathrm{~min}$. Subsequently, washing buffer (200-300 $\mu 1 /$ well) was added and the cell culture plates were washed 3 times. Substrate solution (100 $\mu \mathrm{l} /$ well) was then added, and $30 \mathrm{~min}$ later, $10 \% \mathrm{H}_{2} \mathrm{SO}_{4}(50 \mu \mathrm{l} /$ well $)$ was added. Finally, the absorbance was measured at a wavelength of $450 \mathrm{~nm}$. The experiment was repeated 3 times.

Colony formation assay. At $72 \mathrm{~h}$ post-infection, the RKO and HCT116 cells were plated in 6-well plates at a density of 400 and 500 cells/well, respectively, and cultured in a humidified incubator at $37^{\circ} \mathrm{C}$ with $5 \% \mathrm{CO}_{2}$. After 10 days, the natural colonies that had formed were washed twice with PBS and then stained with crystal violet. The numbers of colonies were counted under light and fluorescence microscopes. The experiment was repeated 3 times.

Flow cytometry analysis. Flow cytometry was used to analyze the cell cycle distributions of the RKO and HCT116 cells following lentiviral infection. The infected cells were collected, fixed with $75 \%$ ethanol, washed with PBS, and stained with propidium iodide (PI) supplemented with RNase overnight at $4^{\circ} \mathrm{C}$. Following staining, the cells were analyzed by flow cytometry. The experiment was repeated 3 times.

Statistical analysis. SPSS 20.0 statistical software (IBM SPSS, Armonk, NY, USA) was used for all statistical analyses. Student t-tests were used to compare the data between two groups. To compare the data of three or more groups, one-way ANOVA was used. The results were presented as means \pm standard deviation (SD), and $\mathrm{P}<0.05$ was considered to indicate statistical significance.

\section{Results}

COPB2 is highly expressed in human colon cancer. To investigate the relationship between COPB2 expression and human
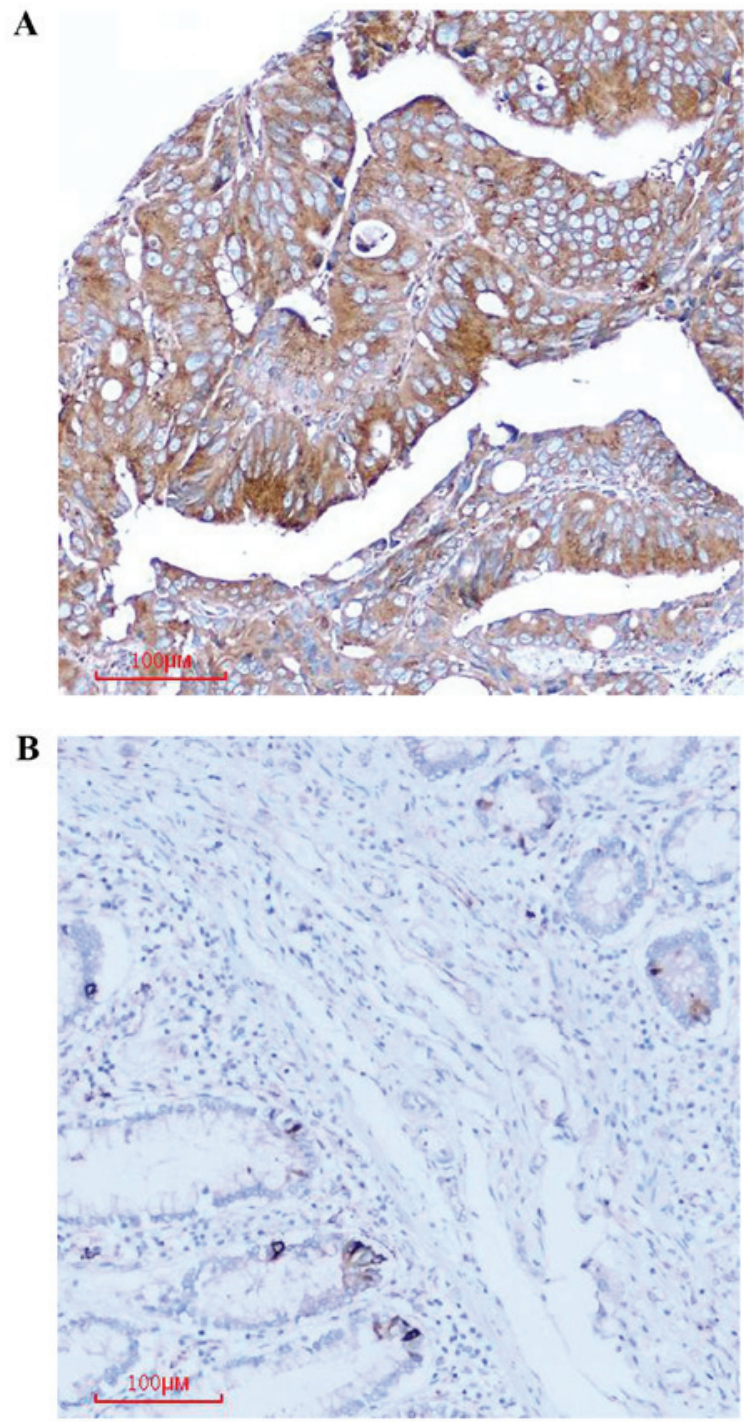

Figure 1. Immunohistochemical analysis of COPB2 expression in colon cancer specimens. (A) High-level expression of COPB2 in colon cancer tissues. (B) Low-level expression of COPB2 in paired adjacent noncancerous tissues. COPB2, coatomer protein complex subunit $\beta 2$.

colon cancer, IHC was used to detect COPB2 expression in 35 colon cancer tissues and adjacent noncancerous tissues. We found that $\mathrm{COPB} 2$ staining was markedly stronger in the colon cancer tissues than in the paracancerous tissues (Fig. 1A). Notably, the COPB2 protein density was determined to be $4.60 \pm 1.418$ in the human colon tissues and $1.17 \pm 1.098$ in the corresponding adjacent tissues $(\mathrm{P}<0.001$; Table I and Fig. 1B). These results indicated that COPB2 may be involved in the pathogenesis of human colon cancer.

COPB2 is positively correlated with pathological grading in human colon cancer. The clinicopathological parameters of 35 patients with human colon cancer, including age, sex, tumor diameter and pathological grade, were examined in this study. As shown in Table II, a significant correlation was observed between the expression of $\mathrm{COPB} 2$ and pathological grade; and the expression of COPB2 was significantly higher in stages III and IV when compared with stages I and II of human colon cancer $(\mathrm{P}<0.01)$. 
Table II. Relationship between COPB2 expression and clinical pathological parameters by IHC staining.

\begin{tabular}{|c|c|c|c|}
\hline Clinical pathological parameters & Case number & Mean \pm SD & P-value \\
\hline \multicolumn{4}{|l|}{ Ages (years) } \\
\hline$\leq 60$ & 17 & $4.530 \pm 1.546$ & \multirow[t]{2}{*}{0.78} \\
\hline$<60$ & 18 & $4.670 \pm 1.328$ & \\
\hline \multicolumn{4}{|l|}{ Sex } \\
\hline Male & 17 & $4.820 \pm 1.510$ & \multirow[t]{2}{*}{0.373} \\
\hline Female & 18 & $4.390 \pm 1.335$ & \\
\hline \multicolumn{4}{|l|}{ Tumor diameter $(\mathrm{cm})$} \\
\hline$\leq 5$ & 23 & $4.65 \pm 1.301$ & \multirow[t]{2}{*}{0.768} \\
\hline$<5$ & 12 & $4.50 \pm 1.679$ & \\
\hline \multicolumn{4}{|l|}{ Pathological grading } \\
\hline $\mathrm{I}+\mathrm{II}$ & 17 & $3.94 \pm 1.391$ & \multirow[t]{2}{*}{$0.002^{\mathrm{a}}$} \\
\hline III+IV & 18 & $5.17 \pm 0.707$ & \\
\hline
\end{tabular}

${ }^{\mathrm{a}} \mathrm{P}<0.01$. COPB2, coatomer protein complex subunit $\beta 2$; IHC, immunohistochemical; SD, standard deviation.

COPB2 gene expression was detected in six human CRC cancer cell lines. To investigate the function of COPB2 in human colon cancer cells, we firstly detected COPB2 expression in six different CRC cell lines (RKO, SW480, HCT116, DLD1, HT29 and SW620) by qPCR. As depicted in Fig. 2, we found that there was relative changes in COPB2 expression in six colon cancer cell lines, especially in HCT116 cells. Therefore, the RKO and HCT116 cell lines were used in subsequent assays.

COPB2 is downregulated in RKO and HCT116 cells by lentivirus-mediated RNAi. The RKO and HCT116 cells were infected with lentiviral-shCOPB2 or -shCtrl. From the level of GFP fluorescence, it was observed that the infection rate was $>80 \%$ in each cell line (Fig. 3A and B). Moreover, RT-qPCR and western blotting showed that the mRNA level and protein level of COPB2 were significantly reduced after the cells were infected with shCOPB2 when compared with the shCtrl and parental groups $(\mathrm{P}<0.01$; Fig. 3C-E). These results suggested that lentivirus-mediated RNAi was able to markedly silence the expression of COPB2 in the RKO and HCT116 cells.

COPB2 silencing inhibits the proliferation and colony formation abilities of RKO and HCT116 cells. To evaluate the influence of COPB2 on the proliferation of RKO and HCT116 cells, an MTT assay was performed. As shown in Fig. 4A and $\mathrm{B}$, we found that cell growth was significantly reduced after infection with lentivirus $(\mathrm{P}<0.001)$. Subsequently, cell proliferation ability was assessed based on BrdU incorporation into cellular DNA. As shown in Fig. 4C, compared with the shCtrl and parental groups, the rates of DNA synthesis in RKO and HCT116 cells following shCOPB2 transduction were significantly reduced $(\mathrm{P}<0.05)$. Additionally, results of the colony formation assay demonstrated that the colony numbers of RKO and HCT116 cells were reduced following shCOPB2 transduction ( $\mathrm{P}<0.01$; Fig. 4D and $\mathrm{E})$. Based on these results, we concluded that COPB2 silencing inhibited

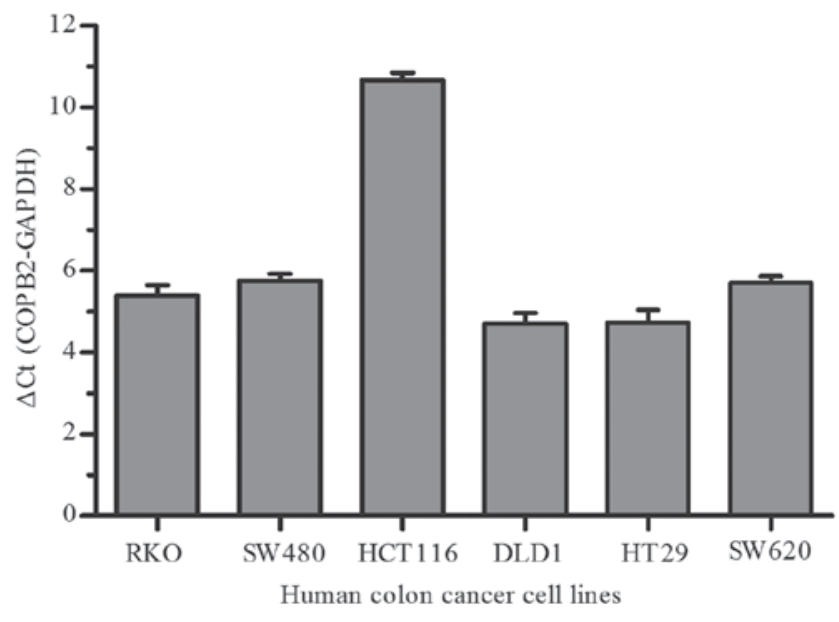

Figure 2. qPCR analysis of COPB2 expression in six human colon cancer cell lines. COPB2 expression was identified in the six different human colon cancer cell lines. COPB2, coatomer protein complex subunit $\beta 2$.

the proliferation and colony-formation abilities of the human colon cancer cells.

COPB2 silencing blocks cell cycle progression in RKO and HCT116 cells. To investigate the mechanism of cell growth inhibition mediated by COPB2 silencing, flow cytometric analysis was performed to analyze the cell cycling of RKO and HCT116 cells following lentivirus infection. In RKO-shCOPB2 cells, it was observed that the percentage of cells in the G1 phase increased, while the percentages of cells in the $\mathrm{S}$ phase and $\mathrm{G} 2 / \mathrm{M}$ decreased $(\mathrm{P}<0.01$; Fig. $5 \mathrm{~A}$ and $\mathrm{B})$. These results indicated that the silencing of COPB2 induced G1 phase arrest and inhibited cell cycle progression in the RKO cells. By contrast, in HCT116 cells, the percentage of cells in the $\mathrm{S}$ phase significantly increased following the silencing of COPB2 $(\mathrm{P}<0.01$; Fig. $5 \mathrm{C}$ and $\mathrm{D})$. This indicated that the HCT116 cells were arrested at the $\mathrm{S}$ phase following COPB2 silencing. 
A RKO

Parental

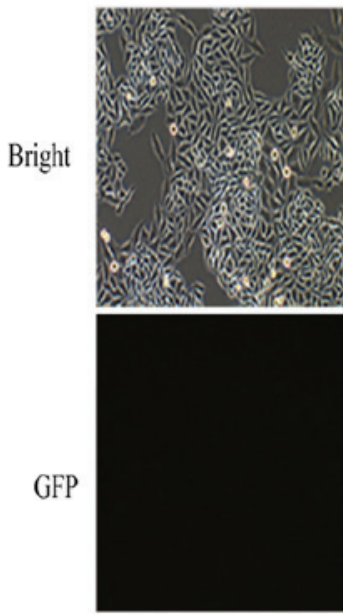

shCtrl
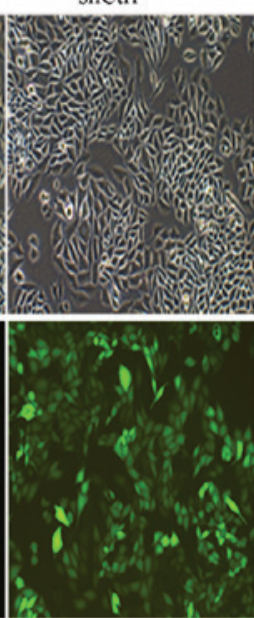

shCOPB2
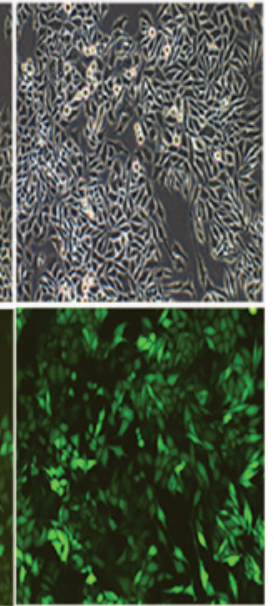

B

B HCT116 Parental

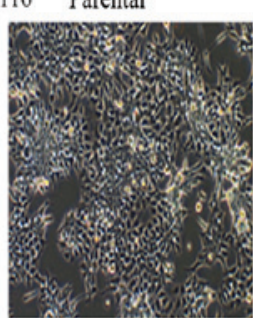

shCtrl

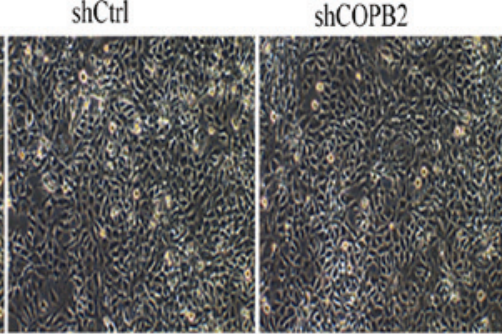

GFP
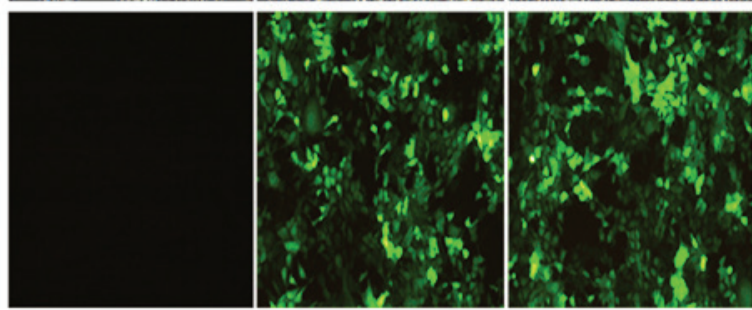

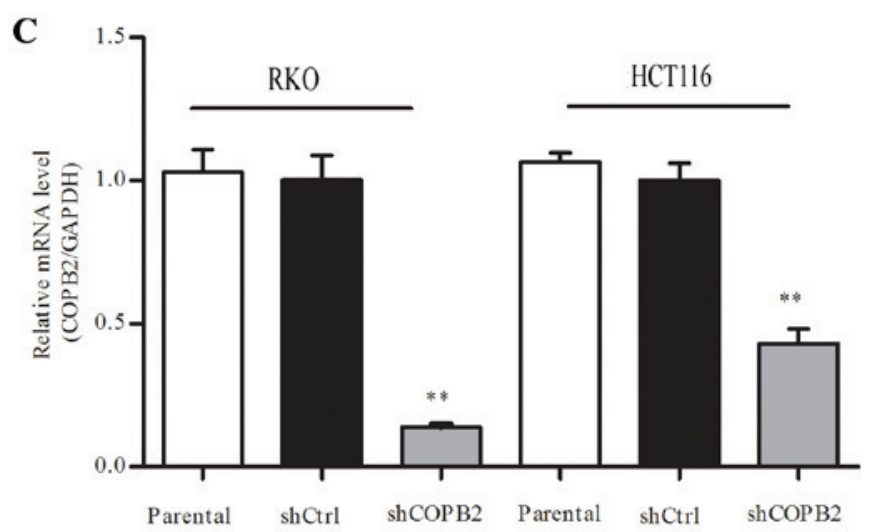

D

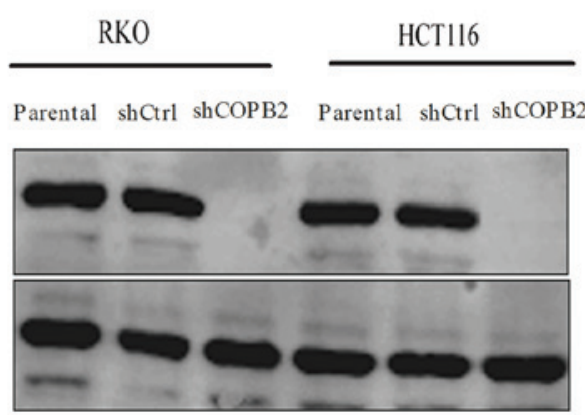

$\mathbf{E}$

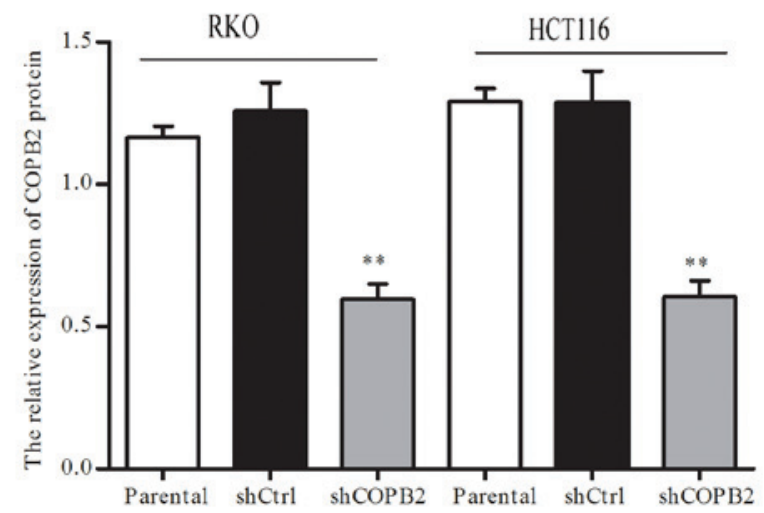

Figure 3. Lentivirus-mediated siRNA transfection can decrease the expression of COPB2 in RKO and HCT116 cells. (A and B) Images of RKO and HCT116 cells 4 days after lentivirus infection. GFP expression in the transfected cells was observed under light and fluorescence microscopes. Upper images, light microscope; lower images, fluorescence microscope; (magnification, x100). (C) Total RNA was extracted 4 days after infection and the relative expression levels of COPB2 mRNA were determined by RT-qPCR. Data represent the mean \pm SD of three independent experiments. ${ }^{* *} \mathrm{P}<0.01$, compared with shCtrl and parental. (D and E) Total cellular proteins were extracted 4 days after infection and measured by western blot analysis using anti-COPB2 and anti-GAPDH (internal control). Data were presented as the mean $\pm \mathrm{SD}$ of three independent experiments. ${ }^{* *} \mathrm{P}<0.01$, compared with shCtrl and parental. COPB2, coatomer protein complex subunit $\beta 2$; RT-qPCR, reverse transcription-quantitative PCR; SD, standard deviation; sh, short hairpin.

COPB2 silencing affects the expression of cell cycle-related proteins and cyclin-dependent kinases inhibitors. To evaluate the potential mechanism underlying the role of COPB2 in cell cycle arrest, western blot analysis was used to assess the protein expression levels of cell cycle-related proteins and cyclin-dependent kinases (CDK) inhibitors. As shown in Fig. 6A-C, silencing of COPB2 increased the protein levels of P16 (CDK inhibitor 2A) and P21 (CDK inhibitor $1 \mathrm{~A})(\mathrm{P}<0.01$ and $\mathrm{P}<0.05$, respectively), and decreased those of cyclin $\mathrm{A} 1$ and A2 $(\mathrm{P}<0.01)$. These results illustrated that COPB2 may be involved in regulating the expression of cell cycle-related proteins and CDK inhibitors in RKO and HCT116 cells. 
A

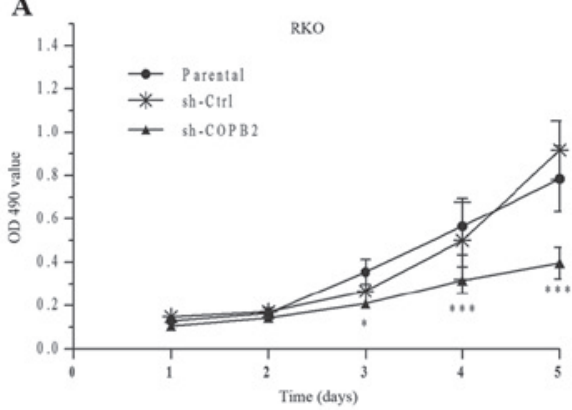

D

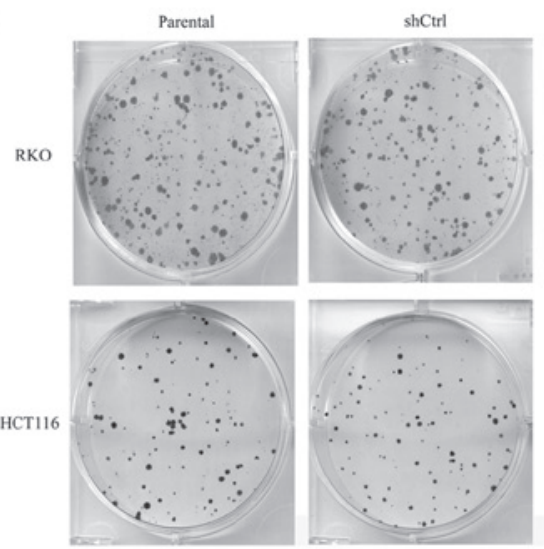

B

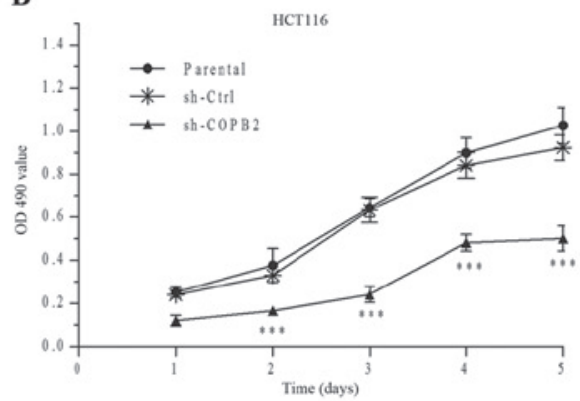

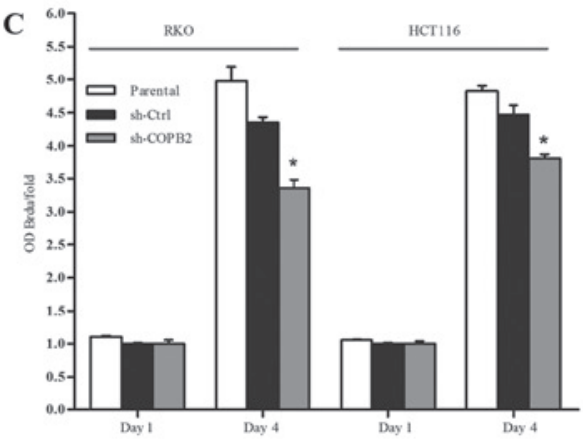

E

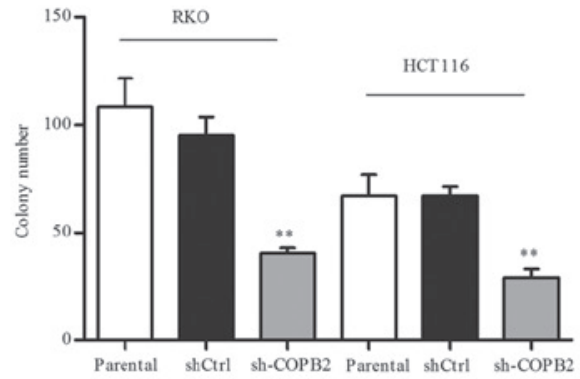

Figure 4. Lentivirus-mediated siRNA inhibits the proliferation and colony-formation abilities of RKO and HCT116 cells. (A and B) The growth curves of RKO and HCT116 cells following lentivirus infection were determined by MTT assay. ${ }^{* * *} \mathrm{P}<0.001$ or ${ }^{*} \mathrm{P}<0.05$. (C) DNA synthesis was measured via a BrdU incorporation assay at days 1 and 4 after infection. ODBrdU/fold=OD450 (day 1 or day 4)/OD450 (day 1). ${ }^{*} \mathrm{P}<0.05$, compared with shCtrl and parental. (D and E) RKO and HCT116 cells were seeded to form colonies. The colony numbers were counted and recorded. Data represent the mean \pm SD of three independent experiments. ${ }^{* *} \mathrm{P}<0.01$, compared with shCtrl and parental. OD, optical density; sh, short hairpin; COPB2, coatomer protein complex subunit $\beta 2 ; \mathrm{SD}$, standard deviation.

A

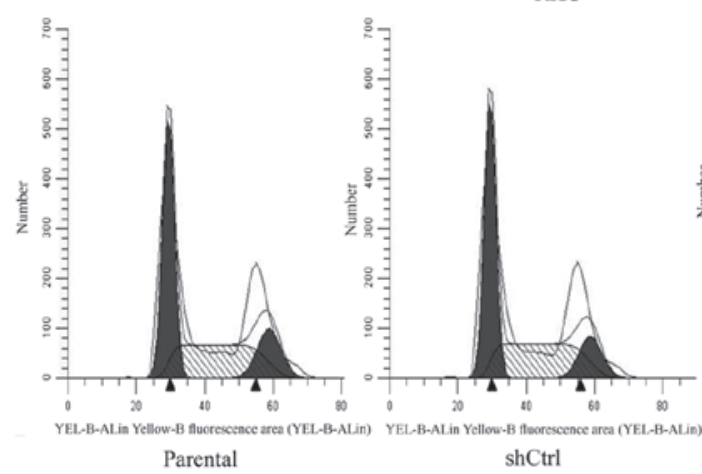

C

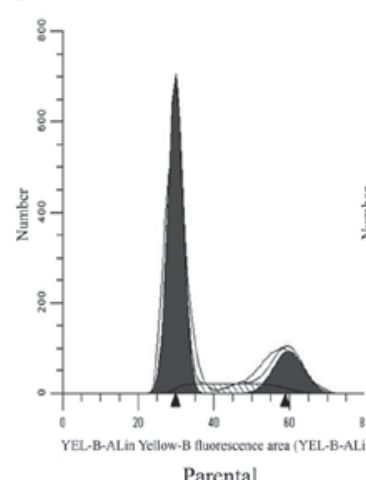

HCT116

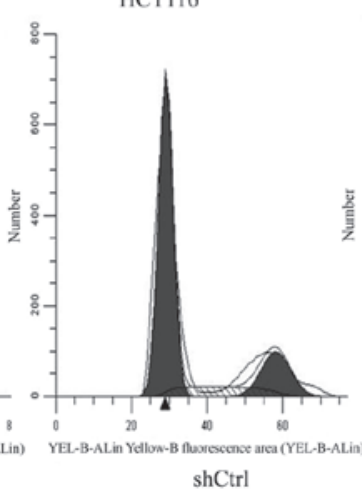

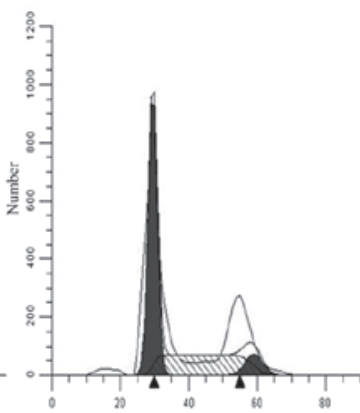

sh-COPB2
B

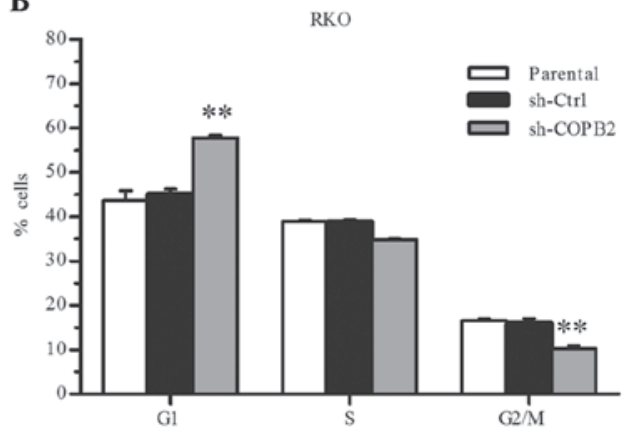

D

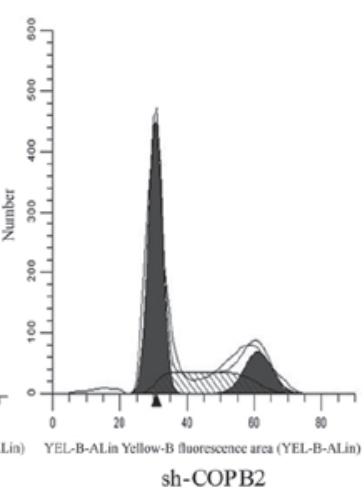

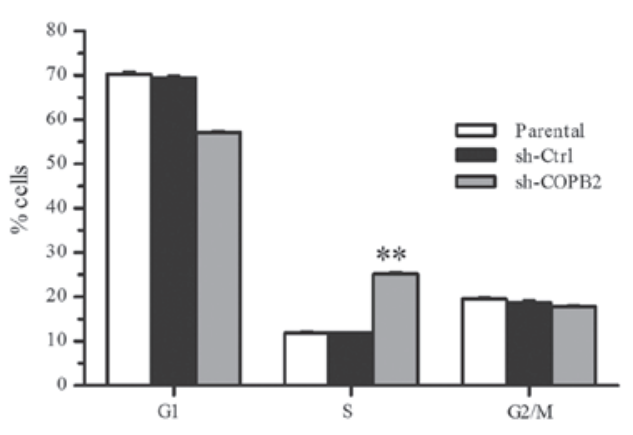

Figure 5. Flow cytometric analysis of cell cycle distribution. Flow cytometric analysis indicated that COPB2 silencing in (A and B) RKO and (C and D) HCT116 cells arrested the cell cycle in $\mathrm{G} 0 / \mathrm{G} 1$ or $\mathrm{S}$ phase, respectively. Data represent the mean $\pm \mathrm{SD}$ of three independent experiments. ${ }^{* *} \mathrm{P}<0.01$, compared with siCtrl and parental. sh, short hairpin; COPB2, coatomer protein complex subunit $\beta 2$; SD, standard deviation. 
A

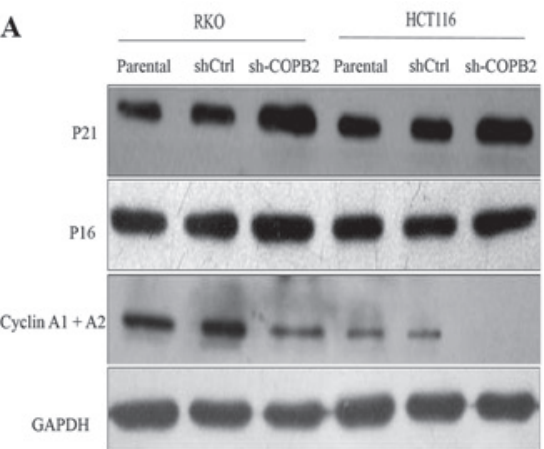

B

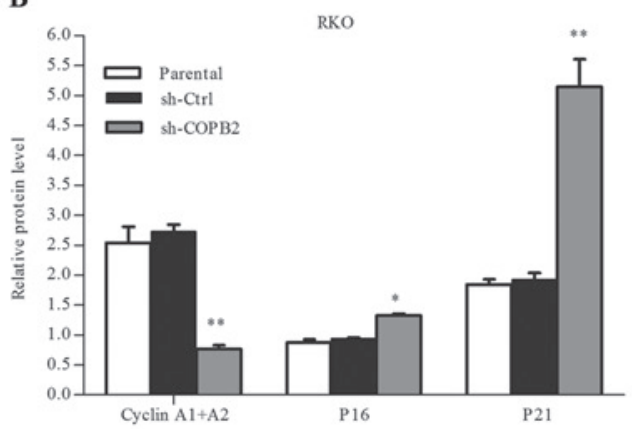

C

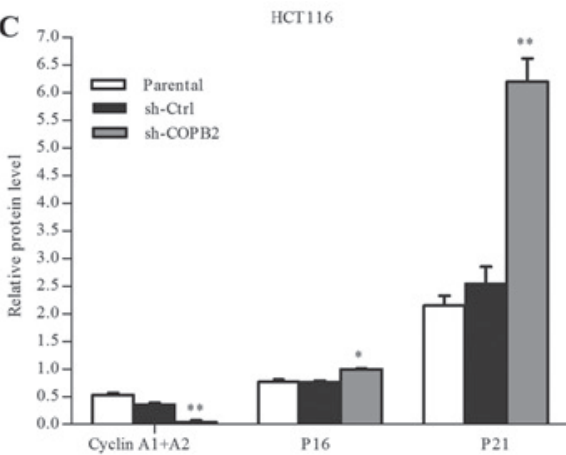

Figure 6. Western blot analysis of cyclin A, P16 and P21 expression in RKO and HCT116 cells. (A-C) After silencing of COPB2, the expression levels of cyclin A were reduced in RKO and HCT116 cells, ${ }^{* *} \mathrm{P}<0.01$ compared with shCtrl and parental; by contrast, the expression levels of P16 and P21 were increased in the RKO and HCT116 cells, ${ }^{*} \mathrm{P}<0.05$ or ${ }^{* *} \mathrm{P}<0.01$ compared with shCtrl and parental. sh, short hairpin; COPB2, coatomer protein complex subunit $\beta 2$.

\section{Discussion}

Comprehensive tumor treatments, involving surgery, chemotherapy, radiotherapy and biotherapy, are becoming more and more important $(17,18)$. Biological therapy for cancer differs from traditional treatment methods. It comprises agents that by virtue of their unique mechanisms of action are able to specifically incite a response against or target malignant cells, and is considered to be an effective method that can be used at each stage of tumor development $(19,20)$. Intracellular transport is important for the functioning of cells, and COPs play an important role in intracellular transport. Therefore, COPs may be biological therapeutic targets in the treatment of human colon cancer. Sudo et al (21) reported that COPA knockdown induced apoptosis and suppressed tumor growth in a mesothelioma mouse model, and thus we hypothesized that COPB2, which was first reported as a novel subunit of the coatomer in 1993 (22), may be correlated with the histogenesis and development of cancer. Mi et al (23) confirmed that COPB2 was over expressed in human prostate cancer and promoted the proliferation of PC-3 cells. These previous findings led us to speculate that COPB2 mightv have functional impacts on other types of cancer cells. In the present study, we first identified that COPB2 was highly expressed in human CRC specimens and in six different colon cancer cell lines. We subsequently investigated the biological function of COPB2 in RKO and HCT116 cells, by using a lentivirus-medicated RNAi method to effectively suppress the expression of COPB2 in the two types of colon cancer cells. We confirmed that the expression of COPB2 was associated with the proliferation and colony-formation abilities of the RKO and HCT116 cells. Furthermore, COPB2 was indicated to regulate the cell cycle; the knockdown of COPB2 resulted in cell cycle arrest in the tumor cells, and by western blotting, we observed that the protein levels of Cyclin A were reduced, with those of P16 and P21 were increased.

However, there were some unresolved factors in the current study, which we will aim to address in future studies. In particular, the molecular mechanism regarding the influence of COPB2 on the proliferation of colon cancer cells, and whether the COPB2 gene is related to tumor migration and invasion, remain unknown and warrant further investigation.
Additionally, the function of the COPB2 gene will be further verified in tumor-bearing mice.

In conclusion, COPB2 was indicated to be essential for the growth of RKO and HCT116 cells through potential regulatory effects on cell cycle progression. Lentivirus-mediated knockdown of COPB 2 could be a potential therapeutic approach for the treatment of human CRC.

\section{Acknowledgements}

The authors would like to express their sincere gratitude to all those who lent their support during the production of this paper. This manuscript was supported by the National Science Foundation of China [(grant no. 81672399(LM)].

\section{References}

1. Vogelstein B, Papadopoulos N, Velculescu VE, Zhou S, Diaz LA Jr and Kinzler KW: Cancer genome landscapes. Science 339: 1546-1558, 2013.

2. Siegel RL, Miller KD and Jemal A: Cancer statistics, 2016. CA Cancer J Clin 66: 7-30, 2016.

3. Brenner H, Kloor M and Pox CP: Colorectal cancer. Lancet 383: 1490-1502, 2014

4. Chen W, Zheng R, Baade PD, Zhang S, Zeng H, Bray F, Jemal A, $\mathrm{Yu}$ XQ and He J: Cancer statistics in China. CA Cancer J Clin 66: 115-132, 2015.

5. Wang S, Zhai Y, Pang X, Niu T, Ding YH, Dong MQ, Hsu VW, Sun Z and Sun F: Structural characterization of coatomer in its cytosolic state. Protein Cell 7: 586-600, 2016.

6. Hara-Kuge S, Kuge O, Orci L, Amherdt M, Ravazzola M, Wieland FT and Rothman JE: En Bloc incorporation of coatomer subunits during the assembly of COP-coated vesicles. J Cell Biol 124: 883-892, 1994.

7. Kuge O, Hara-Kuge S, Orci L, Ravazzola M, Amherdt M, Tanigawa G, Wieland FT and Rothman JE: zeta-COP, a subunit of coatomer, is required for COP-coated vesicle assembly. J Cell Biol 123: 1727-1734, 1993.

8. Orcl L, Palmer DJ, Amherdt M and Rothman JE: Coated vesicle assembly in the Golgi requires only coatomer and ARF proteins from the cytosol. Nature 364: 732-734, 1993.

9. Presley JF, Ward TH, Pfeifer AC, Siggia ED, Phair RD and Lippincott-Schwartz J: Dissection of COPI and Arf1 dynamics in vivo and role in Golgi membrane transport. Nature 417: 187-193, 2002.

10. Beck R, Rawet M, Wieland FT and Cassel D: The COPI system: Molecular mechanisms and function. FEBS Lett 583: 2701-2709, 2009.

11. Lee MC, Miller EA, Goldberg J, Orci L and Schekman R: Bi-directional protein transport between the ER and Golgi. Annu Rev Cell Dev Biol 20: 87-123, 2004. 
12. Ruokun C, Yake X, Fengdong Y, Xinting W, Laijun S and Xianzhi L: Lentivirus-mediated silencing of HSDL2 suppresses cell proliferation in human gliomas. Tumour Biol 37: 15065-15077, 2016.

13. Wang D, Sun SQ, Yu YH, Wu WZ, Yang SL and Tan JM: Suppression of SCIN inhibits human prostate cancer cell proliferation and induces G0/G1 phase arrest. Int J Oncol 44: 161-166, 2014.

14. Bie CQ, Liu XY, Cao MR, Huang QY, Tang HJ, Wang M, Cao GL, Yi TZ, Wu SL, Xu WJ and Tang SH: Lentivirus-mediated RNA knockdown of insulin-like growth factor-1 receptor inhibits the growth and invasion of hepatocellular carcinoma via down-regulating midkine expression. Oncotarget 7: 79305-79318, 2016.

15. Tomuleasa C, Soritau O, Fischer-Fodor E, Pop T, Susman S, Mosteanu O, Petrushev B, Aldea M, Acalovschi M, Irimie A and Kacso G: Arsenic trioxide plus cisplatin/interferon $\alpha-2 b /$ doxorubicin/capecitabine combination chemotherapy for unresectable hepatocellular carcinoma. Hematol Oncol Stem Cell Ther 4: 60-66, 2011.

16. Soritau O, Tomuleasa C, Aldea M, Petrushev B, Susman S, Gheban D, Ioani H, Cosis A, Brie I, Irimie A, et al: Metformin plus temozolomide-based chemotherapy as adjuvant treatment for WHO grade III and IV malignant gliomas. J BUON 16: 282-289, 2011.

17. Buck EA, Haley JD, Thomson S, Mulvihill MJ, Epstein DM and Miglarese MR: Combination anti-cancer therapy. WO patent application 2013152252. Filing date, October 10, 2013.
18. Zhang Z, Wang T, Liu Z, Tang S, Yue M, Feng S, Hu M, Xuan L and Chen Y: Small interfering RNA targeting of the survivin gene inhibits human tumor cell growth in vitro. Exp Ther Med 14: 35-42, 2017.

19. Yang Y and Huang S: Discuss the strengths and weaknesses between tumour biotherapy and chemoradiotherapy. Med Infor 24: 3503-3504, 2011

20. Arora N, Gupta A and Singh PP: Biological agents in gastrointestinal cancers: Adverse effects and their management. J Gastrointest Oncol 8: 485-498, 2017.

21. Sudo H, Tsuji AB, Sugyo A, Kohda M, Sogawa C, Yoshida C, Harada YN, Hino O and Saga T: Knockdown of COPA, identified by loss of function screen, induces apoptosis and suppresses tumor growth in mesothelioma mouse model. Genomics 95: 210-216, 2010.

22. Stenbeck G, Harter C, Brecht A, Herrmann D, Lottspeich F, Orci L and Wieland FT: beta'-COP, a novel subunit of coatomer. EMBO J 12: 2841-2855, 1993.

23. Mi Y, Yu M, Zhang L, Sun C, Wei B, Ding W, Zhu Y, Tang J, $\mathrm{Xia} \mathrm{G}$ and Zhu L: COPB2 is upregulated in prostate cancer and regulates PC-3 cell proliferation, cell cycle, and apoptosis. Arch Med Res 47: 411-418, 2016.

(i) $\Theta$ This work is licensed under a Creative Common Attribution-NonCommercial-NoDerivatives 4.0 International (CC BY-NC-ND 4.0) License. 